\title{
TEMPORAL AND SPATIAL VARIATION OF SOIL EROSION IN CENTRAL YUNNAN PROVINCE, CHINA
}

\author{
LIU, Z. Y. . ${ }^{1,2,3}-$ ZHANG, J. P. ${ }^{1,2,3}-$ WANG, J. L. ${ }^{1,2,3 *}$ \\ ${ }^{1}$ College of Tourism and Geographic Sciences, Yunnan Normal University, \\ Kunming 650500, China \\ ${ }^{2}$ Key Laboratory of Resources and Environmental Remote Sensing for Universities in Yunnan, \\ Kunming 650500, China \\ ${ }^{3}$ Center for Geospatial Information Engineering and Technology of Yunnan Province, \\ Kunming 650500, China \\ ${ }^{*}$ Corresponding author \\ e-mail: jlwang@ynnu.edu.cn \\ (Received 30 $0^{\text {th }}$ Apr 2020; accepted 20 $0^{\text {th }}$ Aug 2020)
}

\begin{abstract}
Soil erosion is one of the major global environmental problems. Understanding the spatiotemporal changes in soil erosion is of great significance to its prevention and control of soil erosion and the optimization of ecological environments. Taking Central Yunnan Province (CYP), China as the study area, multitemporal remotely sensed images, GIS technology and the RUSLE model were used to estimate the amount of soil erosion in the CYP during 1980-2018. The results show the following: (1) During the study period, the soil erosion situation in the CYP showed a growing development trend. With 2005 as a turning point, the area of micro-erosion first decreased and then increased, and the area of soil erosion with mild and above intensity was effectively controlled. (2) Through the global spatial autocorrelation, the spatial distribution of soil erosion intensity in the CYP has significant aggregation, and the global Moran I index is between 0.48 and 0.66 . The areas with moderate and above erosion intensity were mostly distributed in the mountains, northern valleys, and the northwestern and southwestern regions of the CYP. Through the analysis of local spatial autocorrelation, it is also proved that the distribution of intensity soil erosion is mostly related to regional topography.
\end{abstract}

Keywords: soil erosion, RUSLE, temporal and spatial variation, spatial autocorrelation, Moran I index

\section{Introduction}

Central Yunnan Province (CYP) is located on the western Yunnan-Guizhou Plateau and the eastern Yunnan Plateau. Nearly half of the mountainous plains (dams) in Yunnan Province are concentrated in the region, which has abundant soil and good water resources. According to the Bulletin on Soil and Water Conservation of the First National Water Conservancy Census, the type of soil erosion in Yunnan Province is hydraulic erosion. By the end of 2011, the total area of soil erosion was $109,588 \mathrm{~km}^{2}$, accounting for approximately $7 \%$ of the total area of water erosion in China. The area of mild erosion is $44,876 \mathrm{~km}^{2}$, accounting for $40.95 \%$ of the total area of hydraulic erosion; the area of moderate erosion is $3,476 \mathrm{~km}^{2}$, accounting for $31.72 \%$; the area of intense erosion is $15,860 \mathrm{~km}^{2}$, accounting for $14.47 \%$; the area of extremely strong erosion is $8,963 \mathrm{~km}^{2}$, accounting for $8.18 \%$; and the area of intense erosion is $515 \mathrm{~km}^{2}$, accounting for $4.68 \%$. As the core area of Yunnan Province, the soil erosion situation in central Yunnan is not optimistic; thus far, there is still insufficient research on soil erosion in the region. (Ministry of Water Resources of the People's Republic of China, 2013). With sustainable development in mind, soil erosion will lead to the destruction of soil resources, reductions 
in arable land area, and decreases in soil fertility, all of which will affect productivity, deteriorate the ecological environment, destroy infrastructure, increase flood risk by silting up riverbeds, silt up rivers, lakes and reservoirs, and threaten urban and rural safety. Furthermore, soil erosion restricts the sustainability of agricultural production and seriously threatens the survival and development of human beings.

In the field of soil erosion research, the USLE (Universal Soil Loss Equation) model is the most widely used empirical model of soil erosion. According to their own soil erosion situation, many countries and regions have continued to improve and localize the USLE model. For example, the RUSLE (Revised Universal Soil Loss Equation) model was published in the United States in 1997 (Renard et al., 1997); the RUSLE2 model was obtained in 2002 (Gogichaishvili et al., 2014); and in 2008, Kirkby et al. (2010) considered soil infiltration and the impact of climate and climate drivers, and the PESERA (Pan European Soil Erosion Risk Assessment) model was improved by USLE; in 2015, Panagos et al. (2015) used European data for the estimation and scientific evaluation of the localized RUSLE model. From this attempt, the RUSLE2015 model was obtained. Additionally, the G2 model proposed in 2018 (Karydas et al., 2018) is based on the main principles and calculation formulas of the USLE and RUSLE models, and the monthly soil erosion rate model was constructed. The empirical model of soil erosion prediction has gradually been improved, and the localization research and treatment of relevant parameter factors of the model have also deepened; additionally, the obtained soil erosion simulation results are increasingly accurate.

Research on soil erosion in Yunnan Province has been carried out for a long time. Chen (1990) discussed the main influencing factors of soil erosion in the Jinsha River basin in Yunnan Province and proposed corresponding prevention and control measures for existing problems. Yue et al. (2003) used remote sensing and GIS technology to divide the soil erosion index system and use the overlay analysis method to investigate soil erosion in the Zhaotong area. Yao et al. $(2005,2006)$ combined the GIS spatial analysis with traditional statistical analysis with the Lancang River basin in Yunnan Province to study the soil erosion status of the region. Zhou et al. $(2005,2009)$ and $\mathrm{Xu}$ and Zhou (2009) studied the process from a single factor of soil erosion to a later model based on a soil erosion prediction model. Hong et al. (2016) used the indoor artificial simulated rainfall experiment and theoretical analysis to reveal the effect of rainfall intensity, slope and slope length on soil erosion on the Yunnan red soil slope and provided a reference for soil erosion control in the Yunnan red soil area. Yang (2002a,b) and Yang et al. (2002) carried out systematic and in-depth research on soil erosion in the Jinsha River basin in Yunnan Province, and they discussed the relationship between soil erosion control and the sustainable use of land resources (Yang et al., 2004, 2005). Zhang et al. (2004) and Huang et al. (2009) carried out a study on the correlation between soil erosion and soil erosion in the Fuxian Lake watershed. Wang et al. (2016) studied the damage caused by soil erosion in the form of ecological destruction by using the Taojiaxiao River in the Dongchuan District of Kunming city, Yunnan Province, as an example, and proposed conducting research on ecological environment construction in small watersheds, which can improve the local ecological environment. Resilience from disasters can have dividends in terms of economic development and people's lives. Ma et al. (2016) carried out remote sensing monitoring of soil erosion in the Fuxian Lake watershed and determined rainfall was the main influencing factor. The erosion amount of the watershed fluctuated, and it was found that the areas with serious soil erosion were concentrated on the eastern and western sides of Fuxian Lake and on some areas of the southern bank. 
Yang et al. (2016) used soil erosion as one of the basic indicators for constructing a basin-wide land degradation assessment model. The land degradation assessment study of the Fuxian Lake basin was conducted, and it was concluded that the inter-annual variation of land degradation and soil erosion tended to be the same. The correlation between the two was obvious. Zhu et al. (2016) used the case of Lishui County in Yunnan Province as an example to study the soil erosion in the alpine valley area. Based on the spatial differentiation law of regional soil erosion, it was concluded that the unreasonable land use pattern was the main cause of erosion. Ding et al. (2018) estimated the soil erosion in Yunnan Province in 2015 and compared it with the 2004 remote sensing survey data; additionally, the authors carried out dynamic change analysis and concluded that the soil erosion area of the province tended to decrease, among which the areas of mild and moderate erosion reduced significantly.

In terms of erosion models, the RUSLE model is the most commonly used and has a good estimation effect. Scholars have conducted soil erosion studies at the regional, county, watershed and provincial scales in Yunnan Province, but studies have not been conducted in specific administrative and economic regions. In addition, the distribution of soil erosion intensity is used as the research object to discuss. Research on the spatial distribution and agglomeration is also scarce. Therefore, through the study of soil erosion in the CYP, the RUSLE model is used to estimate the regional soil erosion situation from 1980 to 2018.

The objective of the present work was to assess the spatiotemporal variation of soil erosion in the CYP during the 1980-2018 period, using multitemporal remotely sensed images, GIS technology and the RUSLE model, which can provide certain decision support for regional land use planning and eco-environmental engineering management policy formulation.

\section{Materials and methods}

\section{Location and description of the study area}

The CYP includes the 4 cities of Kunming, Chuxiong, Yuxi and Qujing (Fig. 1), and there are 42 counties and urban areas in total. The area is located between $100^{\circ} 43^{\prime}-$ $104^{\circ} 50^{\prime} \mathrm{E}$ and $23^{\circ} 19^{\prime}-27^{\circ} 03^{\prime}$ N. It is adjacent to Guizhou Province and Guangxi Zhuang Autonomous Region in the east, Dali Bai Autonomous Prefecture and Puer city in the west, Honghe Hani Yi Autonomous Prefecture, Wenshan Zhuang and Miao Autonomous Prefecture in the south, and Sichuan Province, Zhaotong city and Lijiang city in the north. The total area is $94,558 \mathrm{~km}^{2}$, accounting for $24 \%$ of the total land area of Yunnan Province. Located in the eastern Yunnan Plateau basin, the terrain is gentle and undulating. The overall terrain is high in the northwest, low in the southeast, and downgraded from the northwest to the southeast. The morphology of each region is widely distributed, and the overall morphology is relatively fragmented (Liu et al., 2017). Located at low latitude and high altitude, the region is controlled by the southwest monsoon and southeast monsoon and is dominated by the mid-subtropical monsoon climate. The region is rich in light energy resources, divided into dry and wet seasons, and rich in heat resources; it has an annual average temperature of $16-22^{\circ} \mathrm{C}$, a summer without heat, and a winter without severe cold. The annual average precipitation ranges from $684.31 \mathrm{~mm}$ to $1777.03 \mathrm{~mm}$, and the overall distribution is higher in the southeast and lower in the rest of the region. Red soils and purple soils are the most widely distributed areas in the region. There are many types of soils in the eastern region, and 
they are scattered and irregular. Red soils are dominant in the central and eastern regions, while purple soils are distributed in patches in the western regions. Vertically, red soils, yellow soils, yellow brown soils, brown soils and sub-soils are distributed successively from low to high in the mountainous region, and there is also alpine meadow soil. The study area with alpine meadow soil belongs to the subtropical evergreen broad-leaved forest area, mainly in the mid-subtropical evergreen broad-leaved forest zone, and is distributed in a small area of the south subtropical monsoon evergreen broad-leaved forest zone, which is rich in forest resources, with an overall coverage rate of approximately $53.8 \%$.

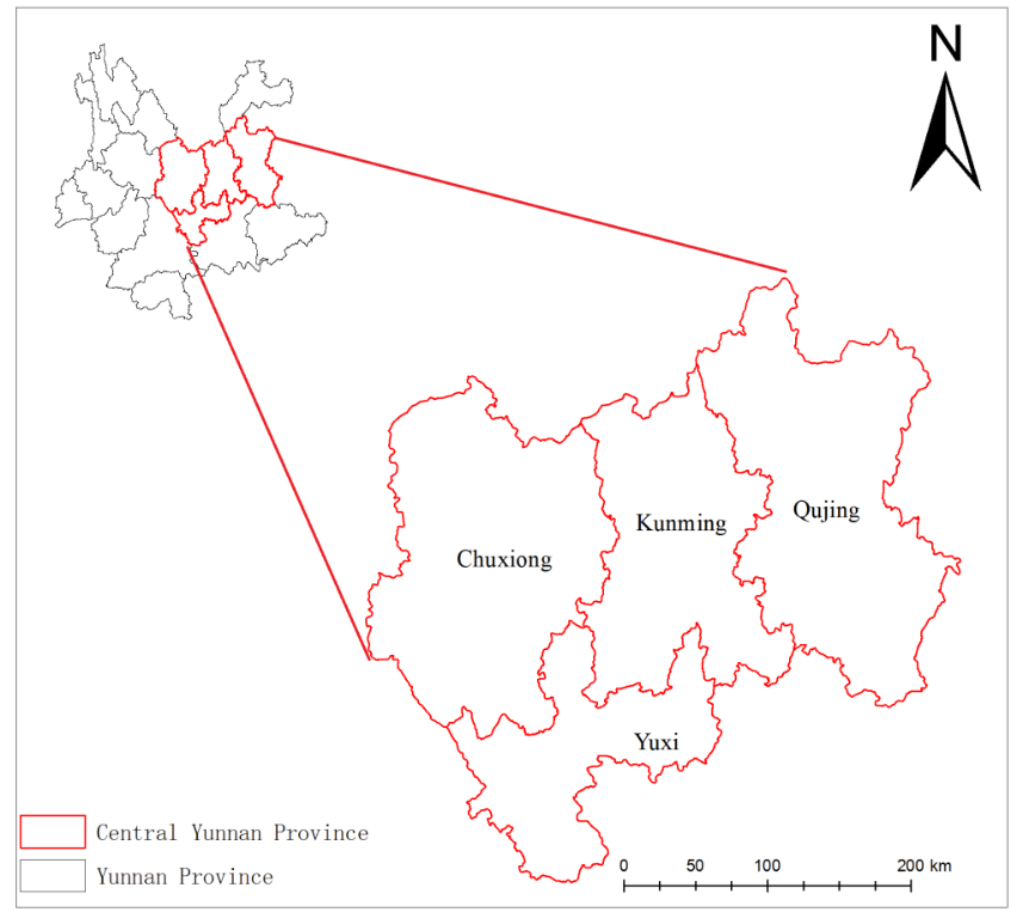

Figure 1. Research Location Map

In recent years, with the continuous development of the social economy and the acceleration of urbanization, various environmental protection measures, such as returning grain plots to forest, have been introduced and implemented. Soil erosion in the CYP has also changed, which has a certain impact on the regional ecological environment. By estimating the long time series of soil erosion, there is important ecological and economic value in studying the changing trend of its quantity and spatial distribution.

\section{Data and preprocessing}

The data sources mainly include (1) basic geographic information data; (2) historical remote sensing image data; and (3) thematic data.

The basic geographic information data are ASTER GDEM (Advanced Spaceborne Thermal Emission and Reflection Radiometer Global Digital Elevation Model) V2 30 m resolution elevation data, which are freely obtained from the geospatial data cloud (http://www.gscloud.cn/). Historical remote sensing image data mainly come from the 
official website of the National Aeronautics and Space Administration (NASA) (https://search.earthdata.nasa.gov/) and the geospatial data cloud (http://www.gscloud.cn/); most free data were downloaded, and some data, such as Landsat OLI, TM, and MSS, were purchased by the instructor team in advance; the satellite images were taken at 1980, 1990, 1995, 2000, 2005, 2010, 2015 and 2018. The thematic data mainly include meteorological, soil, field survey data and remote sensing survey reports on the soil erosion status in the CYP.

The projection coordinates of the source data of soil erosion factors are set as WGS_1984_UTM_Zone_47N, and the geographic coordinates are set as WGS_1984. According to the research needs and the characteristics of the research area, ENVI 5.3 was used to pre-process the remote sensing images, and the land cover remote sensing classification system and the interpretation mark library were established. The image data of the CYP are classified by the maximum likelihood classification method, and the classification results are superimposed with terrain gradient data to provide the terrain characteristics.

\section{Model description}

The Revised Universal Soil Loss Equation (RUSLE), which was an improved form of the Universal Soil Loss Equation (USLE), was used to estimate soil erosion in the CYP. Compared with the USLE, the RUSLE model has a simple structure, a clear physical meaning of parameters, simple calculations, and strong practicability and comprehensiveness.

The mathematical formula of RUSLE is as follows:

$$
A=R \times K \times L S \times C \times P
$$

In the formula, $A$ is the annual average amount of soil erosion per unit area, i.e., the modulus of soil erosion, which is $\mathrm{t} /\left(\mathrm{hm}^{2} \cdot \mathrm{a}\right) ; R$ is the rainfall erosivity factor, and the international general unit is $(\mathrm{MJ} \cdot \mathrm{mm}) /\left(\mathrm{hm}^{2} \cdot \mathrm{h} \cdot \mathrm{a}\right)$; and $K$ is the soil erodibility factor, and the international general unit is $(\mathrm{t} \cdot \mathrm{h}) /(\mathrm{MJ} \cdot \mathrm{mm})$. The other factors are dimensionless: among the $L S$ factors of terrain, $L$ is the slope length factor, $S$ is the slope factor, $C$ is the vegetation cover management factor, and $\mathrm{P}$ is the soil and water conservation measure factor.

\section{Soil erosion factors}

\section{Rainfall erosivity $(R)$ factor}

Rainfall erosivity refers to the potential ability of rainfall to cause soil erosion and is the main dynamic factor leading to soil erosion (Fang et al., 2015). Wischmeier and Smith (1958) proposed a classical method for calculating the rainfall erosivity EI model based on the measured data of rainfall erosion. However, this method is limited by the difficulty of completely obtaining the measured data and cannot be popularized. According to the available monthly meteorological data and the applicability of the model in the CYP, the final calculation formula used in this study is as follows (Silva, 2004):

$$
R=\sum_{i=1}^{12} 73.989 \times\left(\frac{P_{i}^{2}}{P_{a}}\right)^{0.7387}
$$


In the formula, $R$ is the annual rainfall erosivity $(\mathrm{MJ} \cdot \mathrm{mm}) /\left(\mathrm{hm}^{2} \cdot \mathrm{h} \cdot \mathrm{a}\right) ; P_{i}$ is the rainfall $(\mathrm{mm})$ of the i-month; and $P_{a}$ is the average annual rainfall $(\mathrm{mm})$, which is easy to obtain and has high accuracy in complex terrain areas. Based on the data of 39 meteorological stations in the study area provided by the Kunming, Chuxiong, Yuxi and Qujing meteorological bureaus and 21 supplementary station data obtained from the China Meteorological Data Network (http://data.cma.cn/site/index.html) (Table 1, Fig.2), the monthly precipitation data of 65 meteorological stations were analyzed by Kring's spherical hemispherical variation function. The model is interpolated, and the annual rainfall erosivity in the $\mathrm{CYP}$ is calculated according to the $\mathrm{R}$ factor formula. The annual rainfall erosivity in typical years is shown in figures (Fig. 3).

Table 1. Meteorological stations around the CYP

\begin{tabular}{c|c|c|c|c|c|c|c|c|c}
\hline No. & Site Name & No. & Site Name & No. & Site Name & No. & Site Name & No. & Site Name \\
\hline 1 & Chu Xiong & 13 & Kun Ming & 25 & Hui Ze & 37 & E Shan & 49 & Meng Zi \\
2 & Shuang Bai & 14 & Yi Liang & 26 & Fu Yuan & 38 & Xin Ping & 50 & Ping Bian \\
3 & Mo Ding & 15 & Song Ming & 27 & Ma Long & 39 & Yuan Jiang & 51 & Geng Ma \\
4 & Nan Hua & 16 & An Ning & 28 & Lu Liang & 40 & Zhao Yang & 52 & Lin Cang \\
5 & Yao An & 17 & Dong Chuan & 29 & Shi Zong & 41 & Li Jiang & 53 & Yan Shan \\
6 & Da Yao & 18 & Jin Ning & 30 & Luo Ping & 42 & Hua Ping & 54 & Guang Nan \\
7 & Yong Ren & 19 & Tai Hua Shan & 31 & Hong Ta Qu & 43 & Da Li & 55 & Pan Zhi Hua \\
8 & Yuan Mou & 20 & Lu Quan & 32 & Jiang Chuan & 44 & Jing Dong & 56 & Hui Li \\
9 & Wu Ding & 21 & Xun Dian & 33 & Cheng Jiang & 45 & Lan Cang & 57 & Wei Ning \\
10 & Lu Feng & 22 & Qi Lin Qu & 34 & Tong Hai & 46 & Si Mao & 58 & Shui Cheng \\
11 & Fu Min & 23 & Zhan Yi & 35 & Hua Ning & 47 & Jiang Cheng & 59 & Pu An \\
12 & Shi Lin & 24 & Xuan Wei & 36 & Yi Men & 48 & Lu Xi & 60 & Xing Ren \\
\hline
\end{tabular}



Figure 2. Meteorological stations around the CYP 


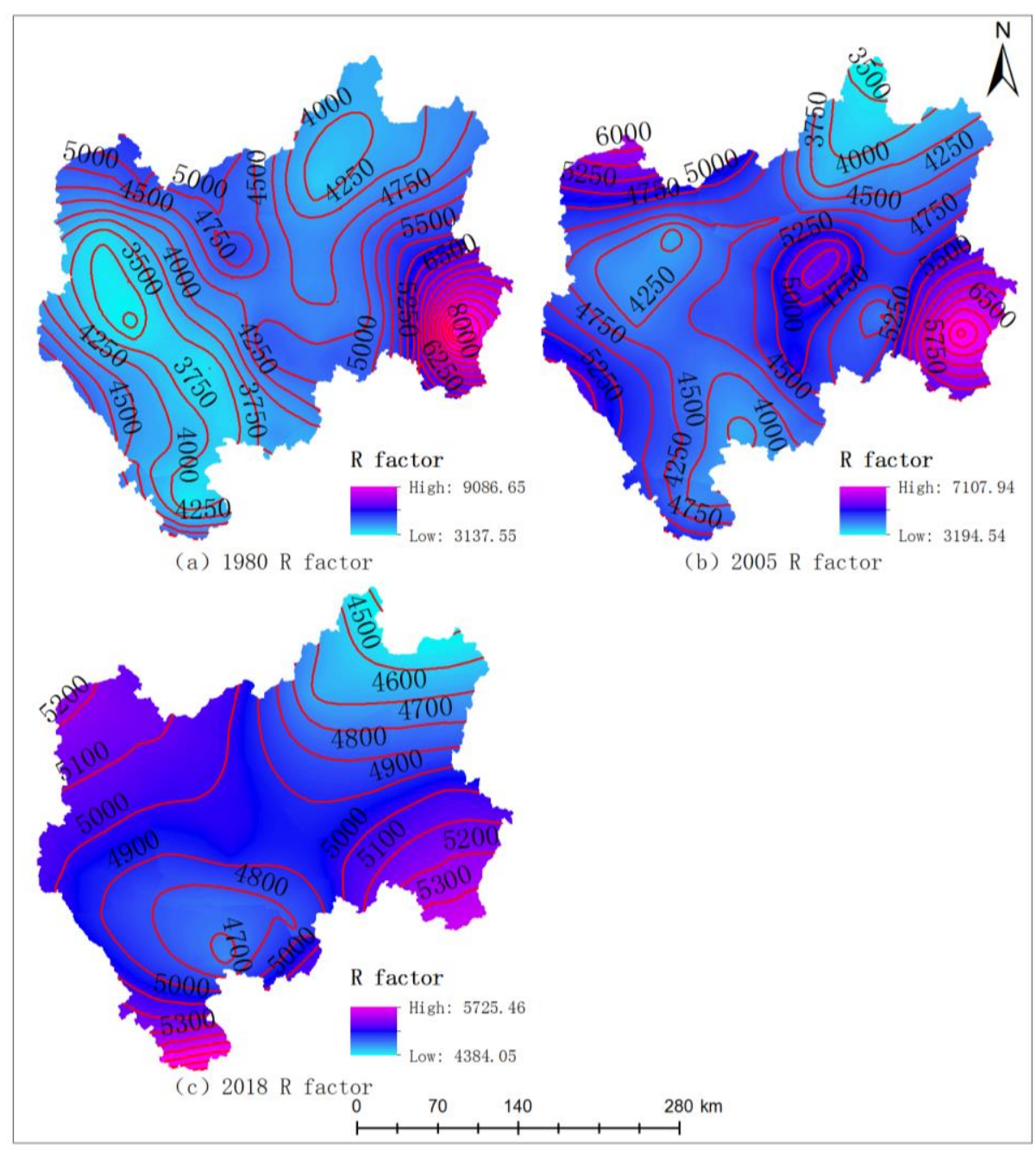

Figure 3. Spatial distribution of rainfall erosivity $R$ factor in the CYP $\left((M J \cdot m m) /\left(h m^{2} \cdot h \cdot a\right)\right)$

\section{Soil erodibility $(K)$ factor}

Among the methods for estimating the $K$ factor of soil erodibility, the Norit diagram and the EPIC (Erosion-Productivity Impact Calculator) method developed by Williams et al. (1983) are represented. The soil data were provided by the Heihe Planning Data Management Center (http://westdc.westgis.ac.cn) based on the World Soil Database (HWSD). The distribution characteristics of soil texture and organic carbon content are detailed in the study area. Therefore, the productivity model EPIC was used to quantitatively calculate the soil erodibility $K$ factor, and the results are revised (Chen et al., 2018) to make the model more appropriate for Chinese soil properties. The formula for calculating the soil erodible factor $K$ by the EPIC model is as follows:

$$
\begin{aligned}
& K_{E P I C}=\left\{0.2+0.3 \exp \left[0.0256 S A N\left(1-\frac{S I L}{100}\right)\right]\right\}\left(\frac{S I L}{C L A+S I L}\right)^{0.3} \times \\
& \left(1.0-\frac{0.25 O C}{O C+\exp (3.72-2.95 O C)}\right)\left(1.0-\frac{0.7 S N}{S N+\exp (22.9 S N-5.51)}\right)
\end{aligned}
$$


The revised formula is as follows:

$$
K=-0.01383+0.51575 K_{E P I C}
$$

In the formula, $K_{E P I C}$ and $K$ are soil erodibility factors before and after amendment, respectively; SAN, SIL, CLA and $O C$ are the percentage of sand, silt, clay and organic carbon in soil, respectively; and $S N=1-S A N / 100$.

The $K$ value calculated by this model is reported in US metric units, and the value is multiplied by $0.1317 \mathrm{rpm}$ to convert it into an international unit $(\mathrm{t} \cdot \mathrm{h}) /(\mathrm{MJ} \cdot \mathrm{mm})$, and the soil erodibility $K$ factor in the CYP region is obtained (Fig. 4).

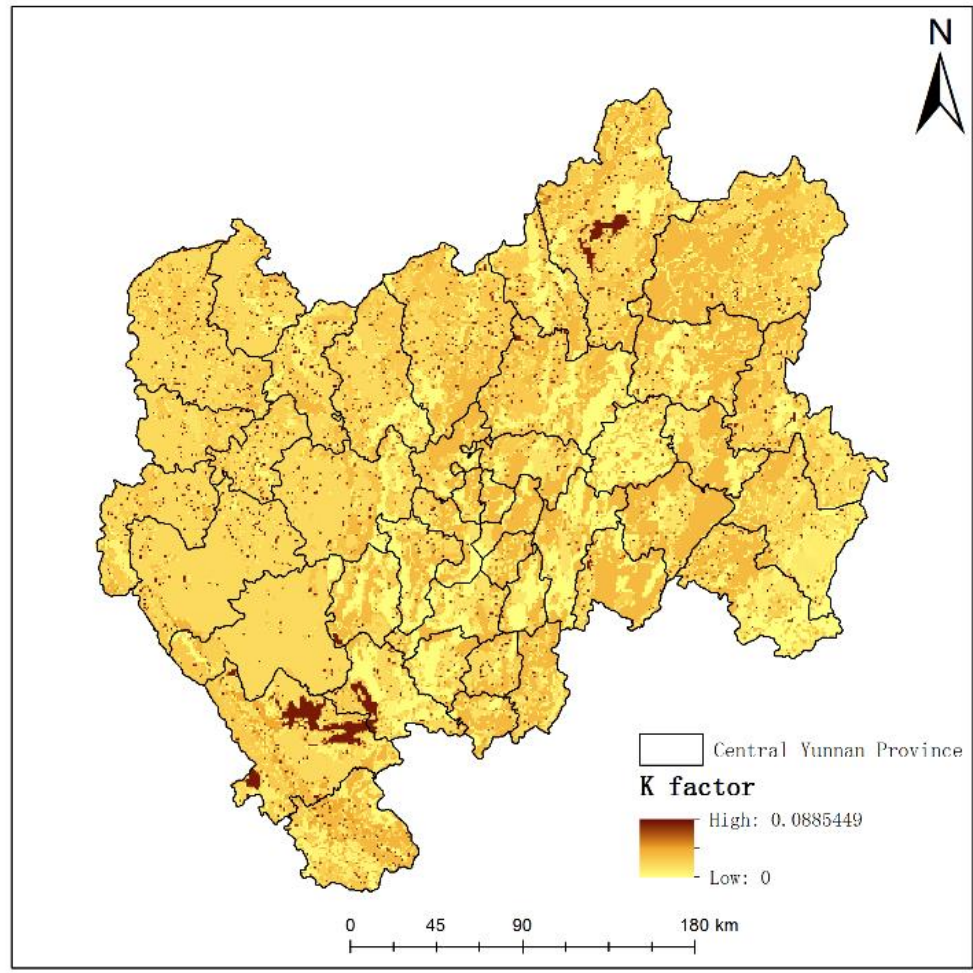

Figure 4. Spatial distribution of soil erosion K factor in the CYP $((t \cdot h) /(M J \cdot m m))$

\section{Slope length and steepness (LS) factor}

In the topographic $L S$ factor, the slope and slope length directly affect the formation and development of the surface soil and the spatial distribution of vegetation, which in turn affects the flow direction, velocity and intensity of surface runoff in the process of surface runoff formation; ultimately, these factors affect the intensity of surface soil erosion. With regard to the calculation of the slope length factor, the method proposed by Wischmeier is more applicable and has higher accuracy; thus, this method is widely used in the field of soil erosion research. Therefore, the formula proposed by Wischmeier and Smith (1965) is used to calculate the $L$ factor of slope length in the CYP (Fig. 5).

$$
L=\left(\frac{\lambda}{22.13}\right)^{\alpha}
$$




$$
\begin{gathered}
\alpha=\beta /(1+\beta) \\
\beta=(\sin \theta / 0.089) /\left[3.0(\sin \theta)^{0.8}+0.56\right]
\end{gathered}
$$

In the formula, $L$ is the slope length factor, $\lambda$ is the slope length, 22.13 is the standard plant slope length (m), $\alpha$ and $\beta$ are the slope length factor indexes, and $\theta$ is the slope.

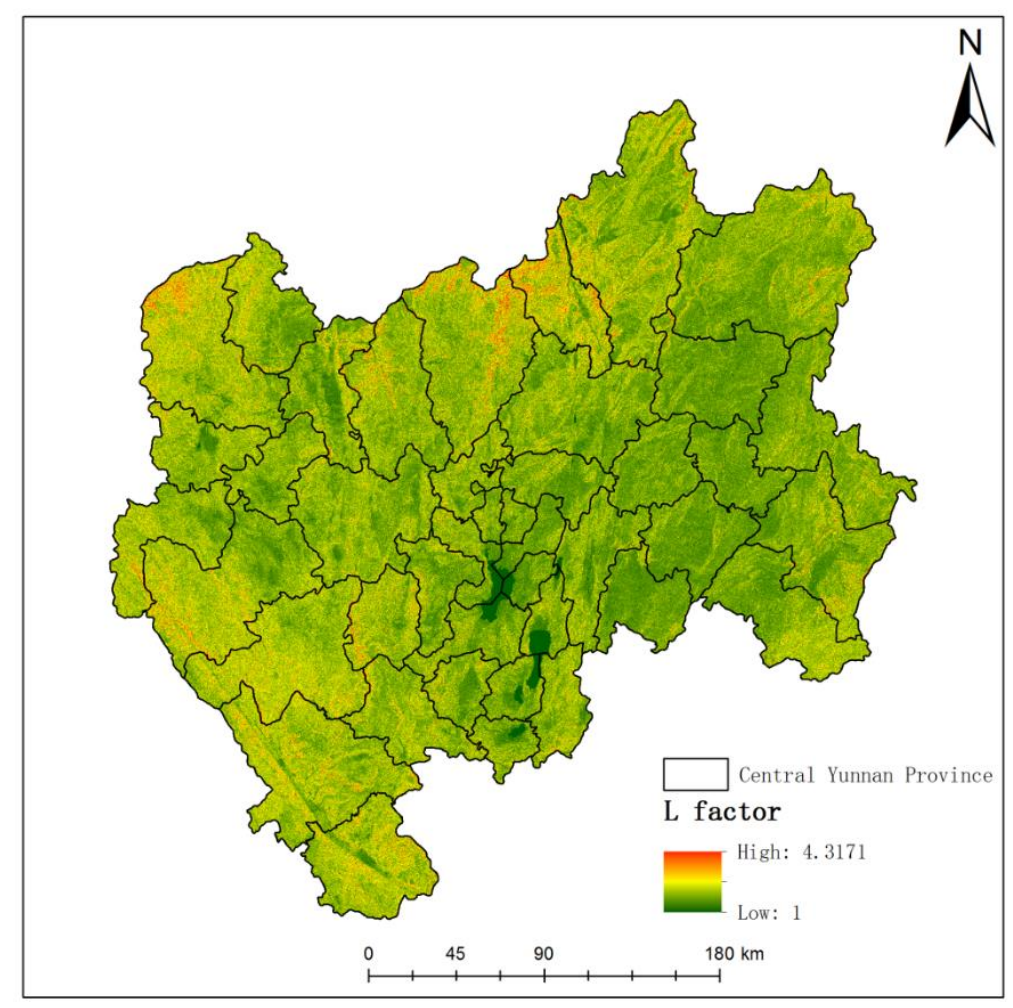

Figure 5. Spatial distribution of slope length L factor in the CYP

In a study of the relationship between soil erosion and slope, McCool et al. (1989) established the linear relationship between gentle slope and soil erosion in 1987, and Liu et al. (2000) added the formula for calculating soil erosion in areas with steep slopes. According to the geomorphological characteristics of the study area and combining these characteristics with the results of McCool et al. and Liu et al., the $S$ factor of the slope in the CYP is calculated in stages (Fig. 6). The formula is as follows:

$$
\left\{\begin{array}{l}
S=10.8 \sin \theta+0.03, \theta<5^{\circ} \\
S=16.8 \sin \theta-0.05,5^{\circ} \leq \theta<10^{\circ} \\
S=21.91 \sin \theta-0.96, \theta \geq 10^{\circ}
\end{array}\right.
$$

In the formula, $\mathrm{S}$ is the slope factor, and $\theta$ is the slope. 


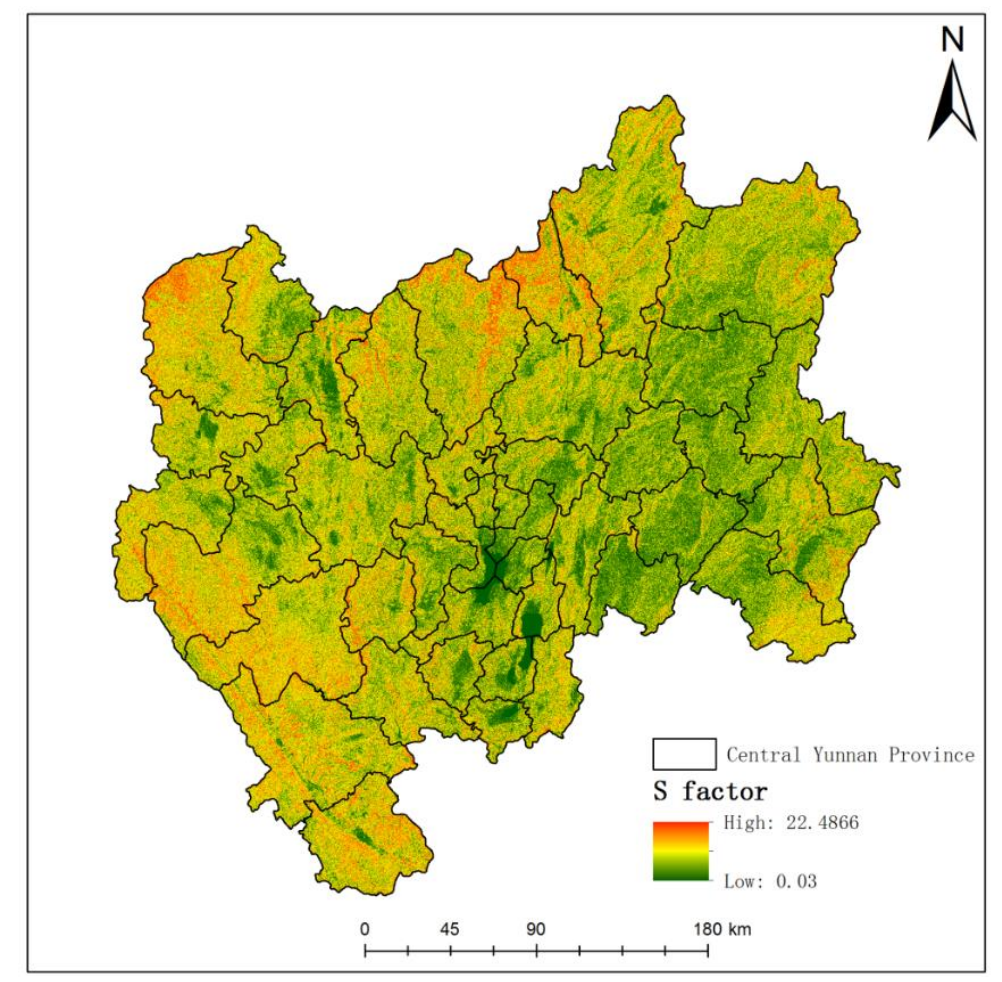

Figure 6. Spatial distribution of slope S factor in the CYP

\section{Vegetation cover and management $(C)$ factor}

The vegetation cover management $C$ factor refers to the standard plot with and without vegetation cover when other conditions are identical, which can reflect the soil erosion caused by different vegetation coverage types. Influence is dimensionless, its value range is $[0,1]$, and its numerical value is directly proportional to the severity of soil erosion. The larger the $C$ factor is, the more serious the soil erosion is. In the RUSLE model, factor $C$ is susceptible to other factors and has a high sensitivity and variable characteristics.

The calculation of the vegetation cover management $C$ factor is divided into three steps: the first step is to extract the normalized difference vegetation index NDVI, the second step is to calculate the vegetation coverage by the NDVI, and the third step is to calculate the $C$ factor value of the vegetation cover management from the vegetation coverage.

We used the pixel dichotomy method to obtain the vegetation coverage of the study area and then used the calculation formula established by Cai et al. (2016) to obtain the $C$ factor of vegetation cover management in the CYP:

$$
\begin{gathered}
F_{c}=\frac{N D V I-N D V I_{\text {soi } 1}}{N D V I_{\text {veg }}-N D V I_{\text {soi } 1}} \\
C=\left\{\begin{array}{l}
1,0 \leq F_{c}<0.096 \\
0.6508-0.3436 \lg \left(F_{c}\right), 0.096 \leq F_{c} \leq 78.3 \\
0, F_{c}>78.3
\end{array}\right.
\end{gathered}
$$


In the formula, $F_{c}$ is the vegetation coverage (\%), NDVI is the normalized difference vegetation index, $N D V I_{\text {soil }}$ represents the $N D V I$ value of no vegetation coverage or bare soil area, $N D V I_{v e g}$ represents the $N D V I$ value of high vegetation coverage area, and $C$ is the vegetation coverage management factor. Through the ArcGIS 10.2 raster calculator, the $C$ factor values of the seven years from 1980 to 2018 were calculated in the CYP. The $C$ factor values for typical years are shown in figures (Fig. 7).

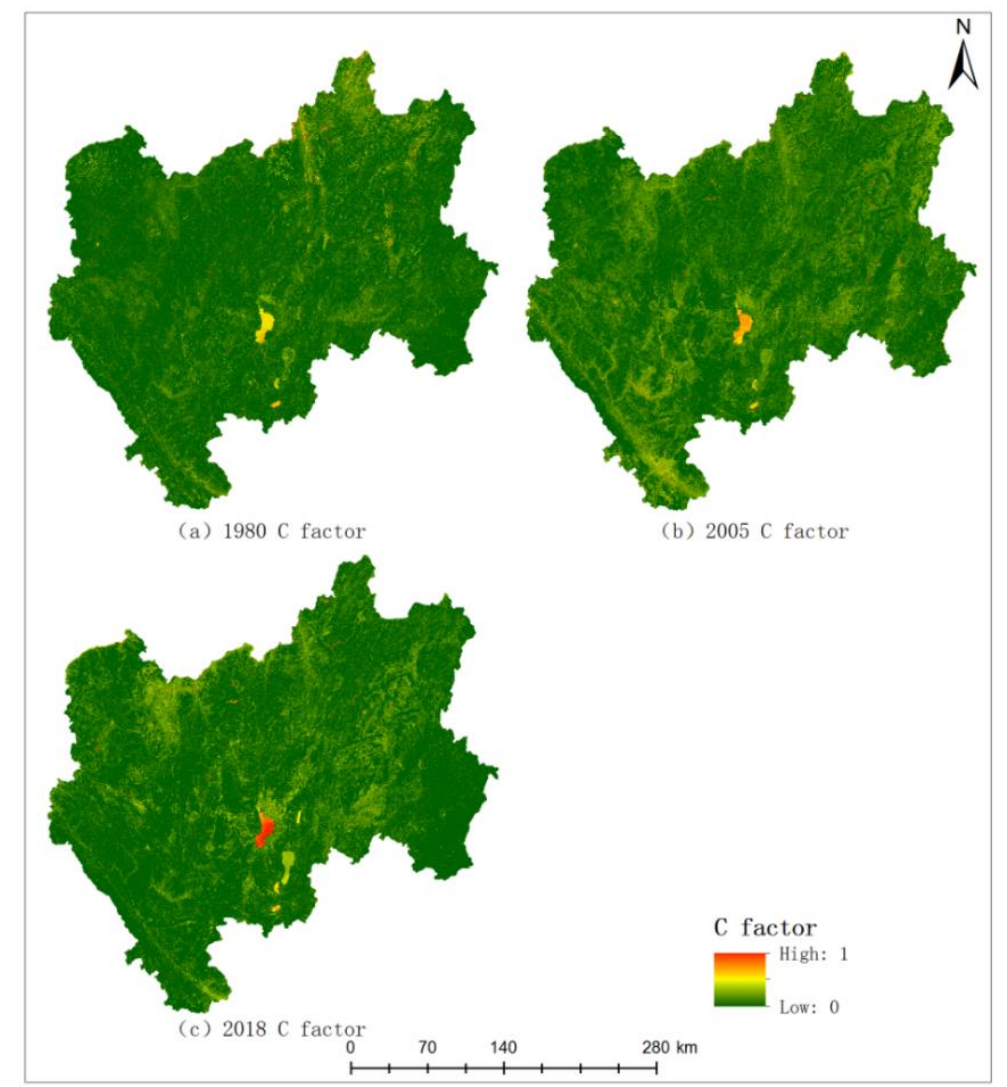

Figure 7. Spatial distribution of vegetation cover management $C$ factors in the CYP

\section{Conservation practice $(P)$ factor}

The soil and water conservation $P$ factor reflects the ratio of soil loss in a certain period of time when the water conservation measures and the standard plots that have not used corresponding measures are in the same situation; the dimension is non-dimensional, and its value is between 0 and 1 . Its value is positively correlated with the possibility of soil erosion. A value of 0 indicates that the probability of soil erosion in this area is almost zero and the soil and water conservation measures are good. A value of 1 indicates that soil erosion is very likely in this area and there are no effective soil and water conservation measures that can be taken.

In China, the $P$ values of different soil and water conservation measures under certain land use types are generally obtained by comparison methods. However, the $P$ values in different regions have large errors, and the values are difficult to determine. Therefore, based on the survey of soil and water conservation status in the CYP, reference is made to the $P$ value table of different soil and water conservation engineering measures in China (Wang et al., 1996), the Handbook of the United States Department of Agriculture, 
the land use type map and vegetation cover map and the research results of predecessors. The corresponding $P$ values are assigned to the local classes (Table 2$)$. The $P$ factors for soil and water conservation measures in typical years are shown in figures (Fig. 8).

Table 2. Soil and water conservation measures $P$ factor value

\begin{tabular}{c|c|c}
\hline Land use types & Code & $\boldsymbol{P}$ factor value \\
\hline Paddy field & 11 & 0.15 \\
& 12 & slope $<5,0.11 ; 5 \leq$ slope $<10,0.22 ;$ \\
Dry land & & slope $<15,0.31 ; 15 \leq$ slope $<20,0.58 ;$ \\
$20 \leq$ slope $<25,0.71 ;$ slope $\geq 25,0.8$ \\
Shrub wood & 21 & 1.00 \\
Arbor forest & 3 & 1.00 \\
Grassland & 4 & 1.00 \\
Water area & 5 & 0.00 \\
Construction land & 61 & 0.00 \\
Bare land & 62 & 1.00 \\
Bare rock & & 0.00 \\
\hline
\end{tabular}

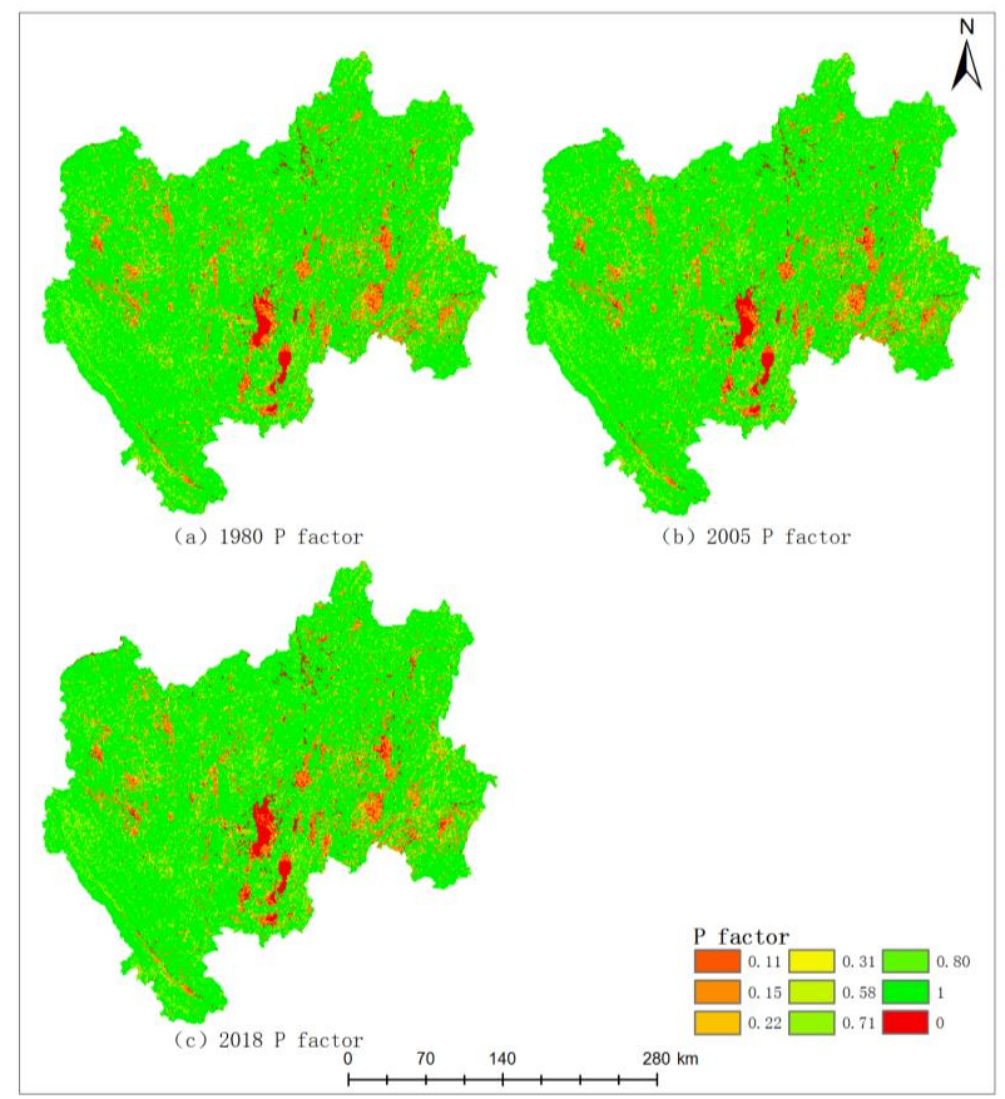

Figure 8. Spatial distribution of soil and water conservation measures $P$ factor in the CYP

\section{Creation of soil erosion hazard map}

The raster layers of each factor are multiplied in the ArcGIS 10.2 raster calculator by the constant 100 to convert the unit $\mathrm{t} /\left(\mathrm{hm}^{2} \cdot \mathrm{a}\right)$ to $\mathrm{t} /\left(\mathrm{km}^{2} \cdot \mathrm{a}\right)$ to obtain the values in the study area. The generated soil erosion raster data (Fig. 9) had a resolution of $30 \mathrm{~m}$. 


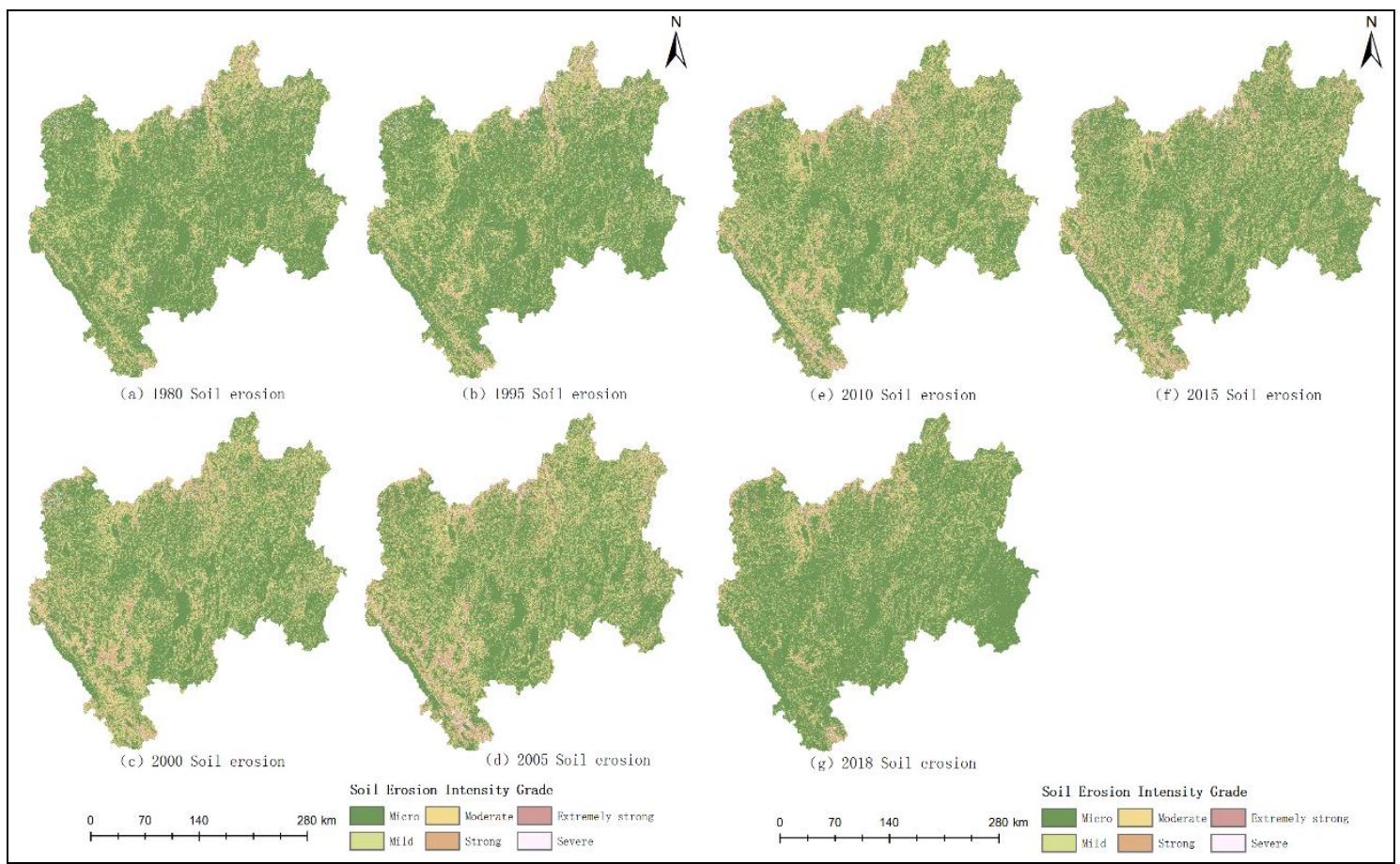

Figure 9. Spatial distribution of soil erosion intensity in the CYP

Comparing the estimated soil erosion results of the study area with the remote sensing survey report of the soil erosion status in Yunnan Province in 1999, it is concluded that the soil erosion modulus values in 2000 are larger than those in 1999; additionally, the proportion of each intensity area was more consistent, the total area of soil erosion increased, and the changes that were presented were associated with the objective law.

According to SL190-2007 "soil erosion classification and classification standard" issued by the Ministry of water resources of the people's Republic of China, the soil erosion in the CYP is classified into six levels (Table 3).

Table 3. Classification standard of soil erosion intensity

\begin{tabular}{c|c|c}
\hline Level & Average modulus of soil erosion $\left.\mathbf{( t /}\left(\mathbf{k m}^{\mathbf{2}} \cdot \mathbf{a}\right)\right)$ & Average loss thickness $(\mathbf{m m} / \mathbf{a})$ \\
\hline Micro & $<500$ & 0.37 \\
Mild & $500 \sim 2500$ & $0.37 \sim 1.9$ \\
Moderate & $2500 \sim 5000$ & $1.9 \sim 3.7$ \\
Strong & $5000 \sim 8000$ & $3.7 \sim 5.9$ \\
Extremely strong & $8000 \sim 15000$ & $5.9 \sim 11.1$ \\
Severe & $>15000$ & $>11.1$ \\
\hline
\end{tabular}

\section{Spatial autocorrelation of soil erosion intensity distribution}

According to the basic law of geographical analysis (Tobler, 1970): "there are corresponding relations between geographical things, among which the closer things are closer than those far away." As a spatial statistical method, spatial autocorrelation can better describe the relationship between geographical objects and measure the degree of aggregation or dispersion among spatial attributes of things. 
General spatial autocorrelation is used to describe the spatial characteristics of spatial element attribute values in the whole area, and reflects the similarity of its neighbor attribute values. It is of great significance for the analysis and description of the distribution characteristics of a specific spatial attribute in the entire area, it is commonly used Moran I index, its expression is (Zhang et al., 2007a):

$$
I=\frac{n \sum_{i=1}^{n} \sum_{j=1}^{n} W_{i j}\left(x_{i}-\bar{X}\right)\left(x_{j}-\bar{x}\right)}{\sum_{i=1}^{n}\left(x_{i}-\bar{X}\right)^{2} \sum_{i=1}^{n} \sum_{j=1}^{n} W_{i j}}
$$

In the formula, $n$ represents the number of spatial objects, $\bar{X}$ is the attribute mean, $X_{i}$ and $X_{j}$ are the attribute values of objects $i$ and $j$, respectively, $W_{i j}$ is the spatial adjacency matrix of objects $i$ and $j, W_{i j}=1$, the two are adjacent, $W_{i j}=0$, the two are not adjacent.

The value range of Moran $I$ index is [-1,1], the closer the value is to 1 , the closer the attributes between objects are, showing a high value aggregation or a low value aggregation relationship; the closer the value is to - 1 , it means that the greater difference in attributes between objects; its value is 0 , which means that there is no spatial autocorrelation between objects and they are randomly distributed.

Compared with the general spatial autocorrelation, the local spatial autocorrelation is to calculate the spatial correlation between each spatial object in the analysis area and its neighboring objects, calculate the local feature differences in the distribution of spatial objects in the analysis and analysis, and reflect the space in the local area Heterogeneity and instability, the calculation formula is (Zhang et al., 2007b):

$$
I_{i}=\frac{\left(x_{i}-\bar{x}\right) \sum_{j=1}^{n} W_{i j}\left(x_{j}-\bar{x}\right)}{\frac{1}{n} \sum_{i=1}^{n}\left(x_{i}-\bar{x}\right)^{2}}
$$

$I_{i}$ is positive, indicating that the spatial object has similar properties to its neighbors; $I_{i}$ is negative, indicating that it is different from the neighboring objects.

According to the spatial distribution data of soil erosion intensity grade in the CYP from 1980 to 2018, a $1000 \mathrm{~m} \times 1000 \mathrm{~m}$ grid cell was created by using ArcGIS10.2, and the area proportion of each erosion intensity grade in each grid was counted as the data source of spatial autocorrelation analysis.

\section{Results and discussion}

\section{Soil erosion factors distribution}

The average $R$ factor in the CYP is between $4,210.96$ and $519.53(\mathrm{MJ} \cdot \mathrm{mm}) /\left(\mathrm{hm}^{2} \cdot \mathrm{h} \cdot \mathrm{a}\right)$. Due to the influence of climate and topography, the spatial distribution is basically bounded by the northeastern and southwestern directions, showing higher $R$ values in the southeast and northwest and lower $R$ values in the northeast and southwest. Most of the 
maximum values are located in the southeastern region, and the maximum value is 9,086.65 $(\mathrm{MJ} \cdot \mathrm{mm}) /\left(\mathrm{hm}^{2} \cdot \mathrm{h} \cdot \mathrm{a}\right)$, which appeared in 1980 ; the minimum values are mostly located in the central and western regions. The minimum value was 2,353.77 $(\mathrm{MJ} \cdot \mathrm{mm}) /\left(\mathrm{hm}^{2} \cdot \mathrm{h} \cdot \mathrm{a}\right)$, which occurred in 2010 .

The $K$ factor ranges from 0 to 0.0885449 , with an average value of 0.0390224 , the numerical range is accurate and reliable. In general, the distribution of $K$ value is relatively uniform.

The spatial distribution of the $L$ and $S$ factors of topographic slope length in the CYP is basically consistent with its overall topography, i.e., northwest to southeast inclination, which shows that the adopted calculation method of the $L$ and $S$ factors can better and quantitatively describe the effect of topography on soil and water loss in the study area.

\section{Soil erosion intensity}

Over the past 38 years in the CYP, soil erosion has generally shown a growing development trend. The average soil erosion modulus ranged from $1000.25 \mathrm{t} /\left(\mathrm{km}^{2} \cdot \mathrm{a}\right)$ to $2064.79 \mathrm{t} /\left(\mathrm{km}^{2} \cdot \mathrm{a}\right)$, and the multi-year average soil erosion modulus was $1624.47 \mathrm{t} /\left(\mathrm{km}^{2} \cdot \mathrm{a}\right)$, which represents a mildly erosive state. Overall, soil erosion shows a fluctuating trend. The two turning years were 2005 and 2015. The area of soil erosion first increased and then decreased, with 2005 as the only turning point. The area of soil erosion in 2005 was the largest, reaching $41,056.04 \mathrm{~km}^{2}$. In 2018 , the modulus of soil erosion and the area of soil erosion reached the lowest values. This result is due to the vigorous implementation of the policy of returning farmland to forest and grassland. People's awareness of environmental protection has also increased. Under the guidance of the government, soil and water conservation measures have been continuously improved and implemented, activities that causes ecological destruction have been effectively curbed, and overall, soil erosion has tended to be good.

From the perspective of the relationship between the average area of erosion intensity and the total area of the region in each period, the CYP is dominated by mild soil erosion, with an average annual area accounting for $48.67 \%$, of which the largest proportion was $55.01 \%$ in 1980 , and the largest area was $18,529.75 \mathrm{~km}^{2}$ in 2000 . The change trend of the area of moderate erosion is consistent with the overall change, and 2005 was the turning point in which the area of erosion transitioned from increasing to decreasing. Except for severe erosion, there is a good correlation between the other grade areas and the total soil erosion area. The correlation coefficients are as follows: mild 0.930; moderate 0.983, which the largest correlation coefficient; strong 0.924; extremely strong 0.929 ; and severe 0.398 , which was the smallest correlation coefficient. From these results, it is possible to estimate the interannual variation of the overall soil erosion status by calculating and analyzing the interannual variation trend of the medium erosion intensity (Table 4).

\section{Temporal change in soil erosion}

To quantitatively describe the change in the erosion grade in central Yunnan from 1980 to 2018 , the transfer matrices of erosion grade between adjacent years and initial years were calculated separately.

From 1980 to 1995, the soil erosion situation deteriorated, and the areas of erosion greater than moderate increased. The moderate erosion area increased most obviously, with an area of $648.47 \mathrm{~km}^{2}$; the micro-degree and mildness experienced a net decrease, among which the micro-erosion transfer was the largest, with a net decrease of $1,445.32 \mathrm{~km}^{2}$, and the area converted to mild erosion reached $2,651.27 \mathrm{~km}^{2}$. The 
proportion of unchanged area of strong erosion was the smallest, with $61.72 \%$ unchanged, and $26.03 \%$ of the original area was converted into extremely strong erosion.

Table 4. Statistics of area and proportion of different soil erosion intensity grades in the CYP $\left(\mathrm{km}^{2}\right)$

\begin{tabular}{c|c|c|c|c|c|c|c|c|c|c|c}
\hline Year & Mild & $\%$ & Moderate & $\mathbf{\%}$ & Strong & $\mathbf{\%}$ & $\begin{array}{c}\text { Extremely } \\
\text { strong }\end{array}$ & $\mathbf{\%}$ & Severe & $\mathbf{\%}$ & $\begin{array}{c}\mathbf{A}_{\text {mean }} \\
\left(\mathbf{t} /\left(\mathbf{k m}^{\mathbf{2}} \mathbf{a}\right) \mathbf{)}\right.\end{array}$ \\
\hline 1980 & 15771.02 & 55.01 & 6945.71 & 24.23 & 2682.65 & 9.36 & 1739.45 & 6.07 & 1531.25 & 5.34 & 1354.95 \\
1995 & 15324.89 & 50.89 & 7593.87 & 25.22 & 3234.93 & 10.74 & 2085.40 & 6.93 & 1874.91 & 6.23 & 1574.83 \\
2000 & 18529.75 & 48.09 & 10538.13 & 27.35 & 5254.52 & 13.64 & 2963.69 & 7.69 & 1248.73 & 3.24 & 1750.40 \\
2005 & 17911.07 & 43.63 & 11191.28 & 27.26 & 6409.78 & 15.61 & 4058.24 & 9.88 & 1485.67 & 3.62 & 2064.79 \\
2010 & 18112.15 & 47.33 & 10347.84 & 27.04 & 5267.43 & 13.76 & 3176.64 & 8.30 & 1362.88 & 3.56 & 1769.54 \\
2015 & 16716.65 & 45.58 & 9454.21 & 25.78 & 5458.70 & 14.88 & 3492.82 & 9.52 & 1556.95 & 4.24 & 1884.56 \\
2018 & 12461.16 & 50.16 & 6748.20 & 27.16 & 3382.80 & 13.62 & 1832.27 & 7.38 & 417.78 & 1.68 & 1000.25 \\
\hline \multicolumn{2}{l}{ Average 16403.81} & 48.67 & 8974.18 & 26.29 & 4527.26 & 13.09 & 2764.07 & 7.97 & 1354.02 & 3.99 & 1628.47 \\
\hline
\end{tabular}

From 1995 to 2000, soil erosion continued to deteriorate, but the overall rate of erosion enhancement slowed. The area of severe erosion decreased $626.93 \mathrm{~km}^{2}$, and the micro-erosion decreased to $8,406.05 \mathrm{~km}^{2}$. The areas of moderate, strong and extremely strong erosion continued to increase, with net increases of $2,941.10 \mathrm{~km}^{2}, 2017.18 \mathrm{~km}^{2}$ and $876.38 \mathrm{~km}^{2}$, respectively.

From 2000 to 2005, the soil erosion situation was the most severe, and the erosion intensity was mostly converted into strong and extremely strong intensities, with net increases of $1,154.47 \mathrm{~km}^{2}$ and $1,093.81 \mathrm{~km}^{2}$, respectively. Under the background of the increase in the area of severe erosion and the continuous reduction in the areas of microdegree and light erosion, the soil erosion in the CYP is deteriorating. The increased area of strong erosion is mainly from micro-degree and light erosion, which contributed to $1,049.78 \mathrm{~km}^{2}$ and $1,035.07 \mathrm{~km}^{2}$, respectively.

From 2005 to 2010, the soil erosion situation improved, and the areas of moderate, strong and extremely strong erosion changed from increasing to decreasing, with net decreases of $841.35 \mathrm{~km}^{2}, 1,140.76 \mathrm{~km}^{2}$ and $879.96 \mathrm{~km}^{2}$, respectively. The area of mild erosion had the largest increase, reaching $2,780.02 \mathrm{~km}^{2}$, and its main source of growth was mild erosion, accounting for $38.19 \%$ of its original area.

From 2010 to 2015, with the overall situation of soil erosion improving, the area of mild erosion maintained a net growth trend, while the areas of strong, extremely strong and severe erosion rebounded, increasing by $191.26 \mathrm{~km}^{2}, 316.19 \mathrm{~km}^{2}$ and $194.36 \mathrm{~km}^{2}$, respectively.

From 2015 to 2018, the overall situation of soil erosion was good, and the area of erosion intensity above the micro-degree had a net decrease; thus, the soil erosion status was effectively contained.

Overall, soil erosion in central Yunnan was effectively controlled from 1980 to 2018. The area of mild erosion in the CYP increased to $3,827.88 \mathrm{~km}^{2}$, and the proportion of the total area of soil erosion increased from $69.68 \%$ in 1980 to $73.73 \%$ in 2018 , representing an increase of $4.05 \%$. The areas of mild, moderate and severe erosion had net reductions of $3,309.87 \mathrm{~km}^{2}, 197.51 \mathrm{~km}^{2}$ and $1,113.47 \mathrm{~km}^{2}$, respectively. The proportion of these three factors in total soil erosion area changed from $55.01 \%$ to $50.16 \%$, with a decrease of $4.85 \%$, from $24.23 \%$ to $27.16 \%$, with an increase of $2.93 \%$, and from $5.34 \%$ to $1.68 \%$, with a decrease of $3.66 \%$, respectively. The results show that in the process of reducing the areas of mild, moderate and severe erosion, the rate of decreasing the area of mild 
erosion was the fastest, followed by that of severe erosion, and the deceleration of moderate erosion was slower than that of the former two.

In summary, during the 38 years, the erosion intensity in the CYP showed a weakening trend, but the changes in erosion grade were more complex. The area of mild erosion increased greatly, the intensity of severe erosion decreased significantly, the growth rate of strong and extremely strong erosion slowed, and the mild and moderate erosion decreased each year, which indicated that the intensity of soil erosion in the region decreased significantly. Soil erosion has been effectively curbed, and the overall erosion situation has improved.

\section{Spatial distribution of soil erosion}

By comparing and analyzing the soil erosion intensity maps of seven periods in the CYP, it can be seen that the distribution of the soil erosion grades in the mountains and valleys in the north and southwest of the CYP is complex and most grades represent extremely strong and severe erosion; however, in the middle and eastern regions with flatter land, mild erosion is dominant, of which Kunming Basin, Songming Basin, Yuxi Basin and Chengjiang Basin have mild erosion. It can be concluded that the spatial distribution of soil erosion intensity is significantly correlated with the topography in the region.

The spatial distribution of soil erosion intensity changes with time, showing a tendency to first deteriorate and then improve. Before 2005, the area of micro-erosion decreased each year. Starting with a uniform distribution, the area with relatively low terrain and relatively small terrain fluctuations in the southeast direction gradually decreased. In the western high terrain and high terrain fluctuation areas, the degree of soil erosion increased, and the intensity distribution became increasingly complex. After 2005, the micro-erosion surface became increasingly complex. The total erosion area above the mild level showed that the erosion area changed from increasing to decreasing, and the erosion could be effectively curbed.

According to the spatial distribution data of soil erosion intensity in the CYP from 1980 to 2018, the global spatial autocorrelation Moran's I index analysis was carried out based on the erosion intensity grade, and Monte Carlo simulation was used to test the spatial distribution of each erosion intensity. It was concluded that the spatial distribution of each erosion intensity showed a significant positive spatial autocorrelation, and spatial object clustering was obvious.

From 1980 to 2018, the numerical range and annual mean value of the overall Moran's I index of the soil erosion grades in central Yunnan were as follows: micro-erosion $0.62 \sim 0.69,0.66$; mild erosion $0.53 \sim 0.61,0.56$; moderate erosion $0.54 \sim 0.63,0.58$; strong erosion $0.58 \sim 0.64,0.61$; extremely strong erosion $0.57 \sim 0.65,0.60$; and severe erosion $0.43 \sim 0.52,0.48$. The Moran's I index of micro-erosion was larger in general, and its spatial aggregation degree was the highest, which indicated that the micro-erosion in the CYP showed a general aggregated distribution during the 38 years; however, the Moran's I index of severe erosion was smaller in general, its spatial distribution was the most dispersed, and it had higher fragmentation.

In the global Moran's I index of the spatial distribution of each grade (Fig. 10), except for the fluctuation of extremely strong erosion, the other five grades showed a fluctuating downward trend. This result indicates that the spatial distribution of soil erosion intensity in the CYP has gradually weakened in the past 38 years, and the degree of fragmentation has become increasingly serious. However, the extremely strong erosion shows that the 
spatial distribution of soil erosion intensity is becoming increasingly concentrated. Based on the spatial distribution of regional soil erosion area and its intensity, it can be seen that under the background of a decreasing area of total erosion, the spatial distribution of soil erosion is becoming increasingly dispersed, and the distribution centers are shifting; however, the distribution centers of extremely strong erosion have been located in the north for a long time because of the high elevation and high land level in the region. The large fluctuation of the potential and the high mountains and valleys are conducive to the occurrence of extremely strong erosion, and the prevention and control of soil erosion has not achieved significant results because of the topographic effects. Therefore, the extremely strong erosion shows an increasing trend in terms of the fluctuation in the Moran's I index.

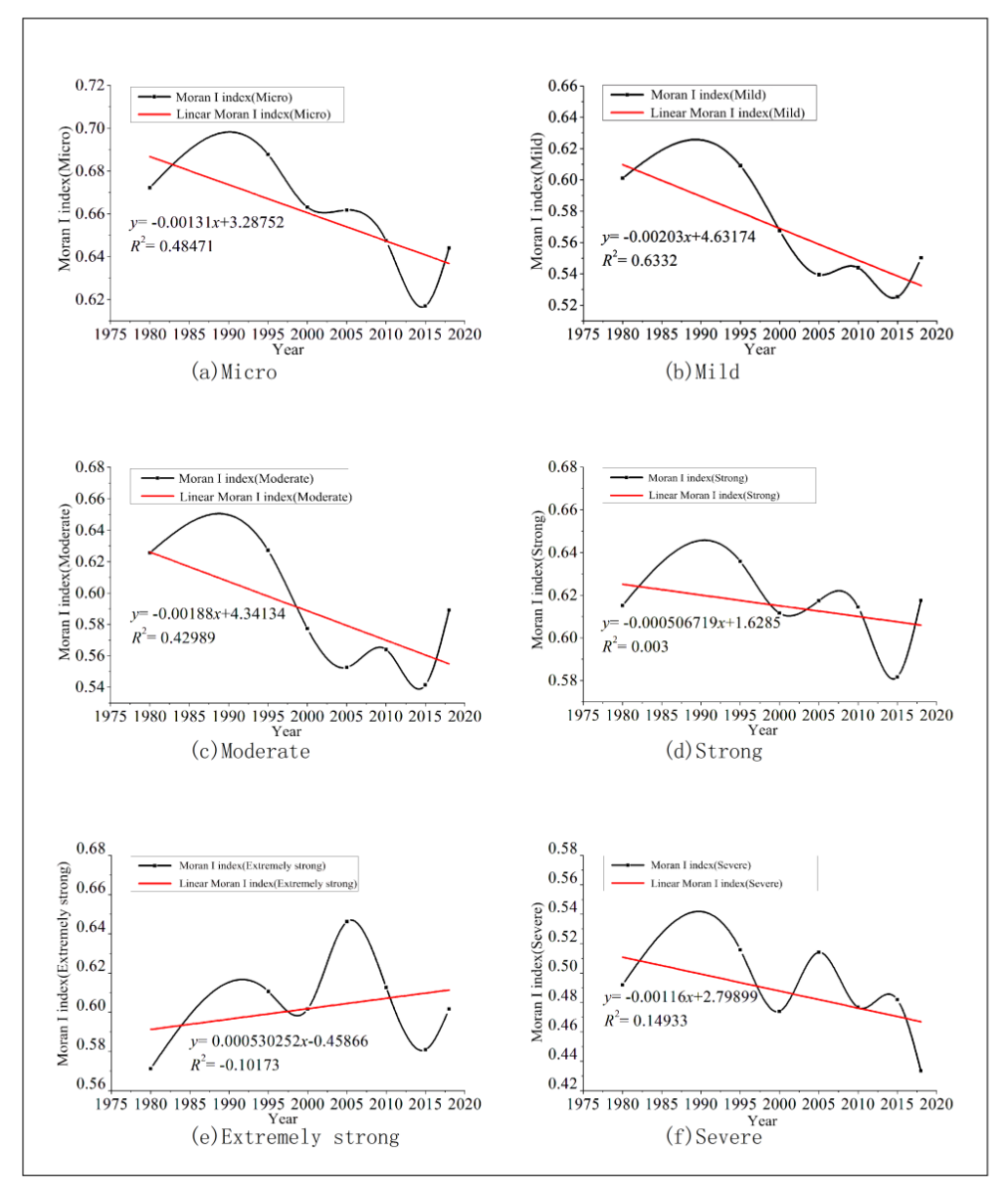

Figure 10. Soil erosion overall Moran's I index in the CYP

In general, the CYP region is affected by its overall topography and morphological distribution, there are different degrees of soil erosion in each region, and the spatial distribution is complex. In 2018, the entire region was dominated by micro-erosion, and extremely strong and severe erosion were still high in the western part of the region; however, the erosion area has been suppressed and reduced, and the overall soil erosion situation has improved significantly. 


\section{Conclusion}

Based on the comprehensive application of remote sensing and GIS technology, the RUSLE model was used to quantitatively characterize the soil erosion factors and the soil erosion status in seven periods for the CYP from 1980 to 2018, and the temporal and spatial changes were analyzed.

(1) Localized soil erosion factors in the CYP. The rainfall erosivity R factor and the topographic LS factor spatial distribution characteristics were more significant. The average $\mathrm{R}$ factor was between 4,120.96 $(\mathrm{MJ} \cdot \mathrm{mm}) /\left(\mathrm{hm}^{2} \cdot \mathrm{h} \cdot \mathrm{a}\right) \quad$ and $5,109.53(\mathrm{MJ} \cdot \mathrm{mm}) /\left(\mathrm{hm}^{2} \cdot \mathrm{h} \cdot \mathrm{a}\right)$, and these values were affected by climate and topography. The spatial distribution changed correspondingly with the regional precipitation, and the overall distribution was more complicated. The spatial distribution of the topographic LS factor was basically consistent with the overall regional topography, e.g., it is inclined from the northwest to the southeast, showing a high numerical distribution in the northwest and a low numerical distribution in the southeast. Its value range is 0.03 97.68.

(2) From 1980 to 2018, the situation of soil erosion in the CYP showed an improving trend. From the aspect of erosion area, using 2005 as the turning point, the area of mild erosion first decreased and then increased, and the area of mild erosion was effectively controlled; from the aspect of the average erosion modulus, the average annual soil erosion modulus was $1,628.47 \mathrm{t} /\left(\mathrm{km}^{2} \cdot \mathrm{a}\right)$, which was categorized as mild erosion. This pattern experienced two turning points; specifically, the value increased each year from 1980 to 2005, declined from 2005 to 2010, rebounded from 2010 to 2015, and returned to a declining trend from 2015 to 2018 . By 2018, the net increase in micro-erosion was three times higher than the increased areas of strong and extremely strong erosion, and these areas accounted for more than $73 \%$ of the total area. The overall erosion situation has been effectively contained.

(3) The spatial distribution of soil erosion intensity in the CYP shows a regular change, and its distribution location has a good correlation with regional topographic fluctuations. The erosion intensity above the moderate level is mainly distributed in the mountains and valleys in the north, northwest and southwest of the region. By calculating and analyzing the global Moran's I index of the spatial distribution of the soil erosion intensity from 1980 to 2018, it is further illustrated that the spatial distribution of the soil erosion intensity presents significant positive spatial autocorrelation overall, and spatial object aggregation is obvious. The spatial distribution law of each erosion intensity in the CYP is highly reliable.

In conclusion, from 1980 to 2018, although there were some fluctuations in the area occupied by each intensity grade of soil erosion in the CYP, the overall trend of development had improved. The area of mild erosion continued to increase, and the average soil erosion modulus remained at a low level. The spatial distribution of the soil erosion intensity had significant aggregation and distribution characteristics, and the location was closely related to the topography. Reviewing the whole research process, the delimitation of the range of the $\mathrm{R}$ factor of rainfall erosivity and the improvement of the accuracy of land use classification will be the main research topics to focus on in followup research; these approaches will enable us to obtain more accurate results of regional soil erosion and provide a more powerful scientific basis for the formulation of regional soil erosion control measures. 
Acknowledgements. This work was supported by Multi-government International Science and Technology Innovation Cooperation Key Project of National Key Research and Development Program of China for the "Environmental monitoring and assessment of land use / land cover change impact on ecological security using geospatial technologies" [grant number: 2018YFE0184300]; the National Natural Science Foundation of China for the "Study on Ecological Safety Assessment and Early Warning in the Central Yunnan" [grant number 41561048]; the Yunnan Provincial Key Project of Philosophy and Social Sciences, "Technological Methods and Empirical Research on County Ecological Assets Measurement in Yunnan Province" [grant number ZDZZD201506]; Young academic and technical leaders project of Yunnan Province [grant number 2008PY056]; and Yunnan Provincial University Science and Technology Innovation Team. We would like to express our great thanks to Huan Deng and Yicheng Liu for their data processing and field work.

\section{REFERENCES}

[1] Cai, C. F., Ding, S. W., Shi, Z. H., Huang, L., Zhang, G. Y. (2016): Study of Applying USLE and Geographical Information System IDRISI to Predict Soil Erosion in Small Watershed. - Journal of Soil and Water Conservation 14(02): 19-24.

[2] Chen, X. Q. (1990): Soil erosion in the upper reaches of Yangtze river (within Yunnan province). - Journal of Soil and Water Conservation.

[3] Chen, B. Z., Qu, J. F., Ge, M. Y., Shen, Y. W., Wang, A. N., Wang, G. B. (2018): Spatiotemporal Analysis on Soil Erosion over Xuzhou City. - Journal of Geo-Information Science 20(11): 1622-1630.

[4] Ding, J. H., Chen, Q. B., Tao, Y. Q., Li, J. Q. (2018): Dynamic Change and Spatial Characteristics of Soil Erosion in Yunnan Province. - Journal of West China Forestry Science 47(06): 15-21.

[5] Fang, G. L., Xiang, B., Zhao, W., Xie, Q., Diao, Zh. Y., Chi, W. F. (2015): Study on Soil Erosion in LaSa River Based on GIS and RUSLE. - Journal of Soil and Water Conservation 29(03): 6-12.

[6] Gogichaishvili, G. P., Kirvalidze, D. R., Gorjomeladze, O. L. (2014): Testing of the hydromechanical prediction model of soil erosion under the conditions of Georgia. Eurasian Soil Science 47(9): 917-922.

[7] He, Y. M., Yang, Z. S., Li, Y. H., Wang, Y. P. (2002): The Survey and Analysis on Farmland Devastated by Soil and Water Loss Disaster in Jinsha River Basin of Yunnan Province. - Journal of Mountain Science 20: 31-35.

[8] Hong, B., Zhang, Z., Huang, Y., Liang, J., Qiu, G. (2016): Erosion Characteristics of Yunnan Laterite Under Artificial Rainfall Conditions. - Bulletin of Soil and Water Conservation 36(04): 118-123.

[9] Huang, D. F., Zheng, X. M., Zhou, L. M., Wang, N., Wang, H. (2009): Comprehensive Analysis of the Soil Erosion in Fuxian Lake Basin Based on DEM. - Research of Soil and Water Conservation 16(04): 76-79.

[10] Karydas, C. G., Panagos, P. (2018): The G2 erosion model: An algorithm for month-time step assessments. - Environmental Research 161: 256-267.

[11] Kirkby, M. J., Irvine, B. J., Jones, R. J. A., Govers, G., Team, P. (2010): The PESERA coarse scale erosion model for Europe. I. - Model rationale and implementation. - European Journal of Soil Science 59(6): 1293-1306.

[12] Li, Y. H., He, Y. M., Yang, Z. S. (2002): The Calculatical Methods and Analysis on the Regional Characteristics of Direct Economic Loss of Soil Erosion in Jinsha River Basin of Yunnan Province. - Journal of Mountain Science 20: 36-42.

[13] Li, Y. H., He, Y. M., Yang, Z. S. (2002): Analysis on Reduced Grain Yield from Agricultural Natural Disaster in Jinsha River Basin of Yunnan Province. - Journal of Mountain Science 20: 43-48.

[14] Liu, B. Y., Nearing, M. A., Shi, P. J., Jia, Z. W. (2000): Slope length effects on soil loss for steep slopes. - Soil Science Society of America Journal 64(5): 1759-1763. 
[15] Liu, Z. Y., Wang, J. L. (2017): Basic Geomorphic Types in Central Yunnan Province Based on SRTM DEM. - Yunnan Geographic Environment Research 29(06): 9-15.

[16] Ma, L. C., Wang, J. L., Li, S. H., Zhou, J. S., Jin, B. X. (2016): Remote Sensing Monitoring of Soil Erosion in Fuxianhu Lake Basin. - Research of Soil and Water Conservation 23(03): 65-70.

[17] McCool, D. K., Foster, G. R., Mutchler, C. K., Meyer, L. D. (1989): Revised Slope Length Factor for the Universal Soil Loss Equation. - Transactions of the Asae 30(5): 1387-1396.

[18] Ministry of Water Resources of the People's Republic of China (2013): Bulletin of the First National Water Conservancy Survey on Soil and Water Conservation. - Bulletin of the Ministry of Water Resources of the People's Republic of China 02: 58-61.

[19] Panagos, P., Borrelli, P., Poesen, J., Ballabio, C., Lugato, E., Meusburger, K., Montanarella, L., Alewell, C. (2015): The new assessment of soil loss by water erosion in Europe. - Environmental Science and Policy 54: 438-447.

[20] Renard, K. G., Foster, G. R., Weesies, G. A., Mccool, D. K., Yoder, D. C. (1997): Predicting soil erosion by water: a guide to conservation planning with the Revised Universal Soil Loss Equation (RUSLE). - Agricultural Handbook, Agricultural Research Service, USA.

[21] Silva, A. M. D. (2004): Rainfall erosivity map for Brazil. - Catena 57(3): 251-259.

[22] Tobler, W. R. (1970): A Computer Movie Simulating Urban Growth in the Detroit Region. - Economic Geography 46(sup1): 234-240.

[23] Wang, W. Z., Jiao, J. Y. (1996): Quantitative evaluation on factors influencing soil erosion in China. - Bulletin of soil and water conservation 16(5): 1-20.

[24] Wang, H. F., Wang, J., Tai-Neng, L. (2014): Preliminary Research and Analysis of Ecological Environment Construction in the Small River Basin-A Case Study in Taojia Small River, Yunnan Province. - Research of Soil and Water Conservation 21(06): 256259.

[25] Williams, J. R., Renard, K. G., Dyke, P. T. (1983): EPIC-A New Method for Assessing Erosion's Effect on Soil Productivity. - Journal of Soil and Water Conservation 38(5): 381383.

[26] Wischmeier, W. H., Smith, D. D. (1958): Rainfall energy and its relationship to soil loss. - Transactions American Geophysical Union 39(2): 285-291.

[27] Wischmeier, W. H., Smith, D. D. (1965): Predicting rainfall-erosion losses from cropland east of the Rocky Mountains: a guide to conservation planning. - Agricultural Handbook, Agricultural Research Service, USA.

[28] Xu, Q. Y., Zhou, Y. (2009): Study on Prediction of Soil Erosion Based on GIS and USLETaking Dahongshan Iron Mine at Xinping of Yunnan Province as A Case Study. - Research of Soil and Water Conservation 16(04): 72-75.

[29] Yang, Z. S. (2002a): Study on Soil Loss Equation in Jinsha River Basin of Yunnan Province. - Journal of Mountain Research 20: 1-9.

[30] Yang, Z. S. (2002b): Analysis on main characteristics of soil erosion in Jinsha river basin of Yunnan province. - Journal of mountain science 20: 80-87.

[31] Yang, Z. S., Liang, L. H., Wang, Y. P. (2002): Analysis on Main Characteristics of Soil Erosion in Jinsha River Basin of Yunnan Province. - Journal of Mountain Research 20: 10-17.

[32] Yang, Z. S., He, Y. M., Li, Y. H., Zhang, Y. L., Wang, Y. P. (2004): Land use change and soil erosion control in dry-hot valley zone in the middle reaches of Jinsha river during 19602000: -a case study in Binchuan county, Yunnan province. - Progress in geography 23(2): 16-26.

[33] Yang, Z. S., Liu, Y. S., Lu, Y. X. (2005): Sustainable Use of Land Resources and Soil Erosion Control in Mountainous Areas. - Resources Science 27(6): 146-150.

[34] Yang, C., Wang, J. L., Li, S. H., Wang, L. X., Ma, L. C., Pan, J. Y., Liu, G. J. (2016): Land Degradation Dynamic Remote Sensing Monitoring of Fuxian Lake Basin. - Remote Sensing Technology and Application 31(2): 388-396. 
[35] Yao, H. R., Yang, Z. F., Cui, B. S. (2005): Soil Erosion and Its Environmental Background at Lancang Basin of Yunnan Province. - Bulletin of Soil and Water Conservation 25(4): 510.

[36] Yao, H. R., Yang, Z. F., Cui, B. S. (2006): Spatial analysis on soil erosion of Lancang River Watershed in Yunnan Province under the support of GIS. - Geographical Research 25(3): 421-429.

[37] Yue, C. R., Tian, K., Xu, T. (2003): A Study on Soil Erosion Investigation by Using Remote Sensing and GIS in Zhaotong Prefecture. - Bulletin of Soil and Water Conservation 23(2): 36-39.

[38] Zhang, J. P., Yang, S. H., Wang, B. R. (2004): Comparative Research on Water and Soil loss in Different Vegetation Areas in Phosphate Mining Areas in Fuxianhu Lake. - Yunnan Environmental Science 23(3): 42-44.

[39] Zhang, S. L., Zhang, K. (2007a): Comparison between General Moran's Index and GetisOrd General G of Spatial Autocorrelation. - Acta Entiarum Naturalium Universitatis Sunyatseni 46(4): 93-97.

[40] Zhang, S. L., Zhang, K. (2007b): Contrast Study on Moran and Getis-Ord Indexes of Local Spatial Autocorrelation Indices. - Journal of Geodesy and Geodynamics 27(3): 31-34.

[41] Zhou, Y., Fu, Y. B., Xu, Q. Y., Zeng, Z. T. (2005): Study on Forest-Grass Vegetation of Soil Erosion Control-Taking Dahongshan Iron Mine at Xinping of Yunnan Province as an Example. - Journal of Kunming University of Science and Technology 30(6): 68-72.

[42] Zhou, Y., Ding, W. R., Zeng, H. P., Wang, J. (2009): Influence of Land-Use in Longitudinal Range-Gorge Region in Yunnan on Soil Erosion-Taking Three Drainage Areas of Heihuijiang, Longchuanjiang and Panlonghe as Examples. - Journal of Kunming University of Science and Technology 34(4): 68-72.

[43] Zhu, J., Li, Y. M., Jiang, D. (2016): A Study on Soil Erosion in Alpine and Gorge Region Based on GIS and RUSLE Model-Taking Lushui County of Yunnan Province as an Example. - Bulletin of Soil and Water Conservation 36(3): 277-283. 